\title{
А.М. Стрельцов
}

\section{АКСИОЛОГИЧЕСКАЯ ПРОБЛЕМАТИКА ПРИЗВАНИЯ ФИЛОСОФА В «СОКРАТИЧЕСКИХ ДОСТОПРИМЕЧАТЕЛЬНОСТЯХ» И.Г. ГАМАНА}

\begin{abstract}
В статье разбирается сочиально-политическая проблематика дебютного трактата И.Г. Гамана, в котором он отвергает трудовую этику Просвещения, а такюе пытается разрушить понятие публики как общественного идеала. С точки зрения Гамана, философ, относящийся серьёзно к своему призванию, не может рассчитьвать на широкое общественное признание, но долюен быть готов к жизни, полной лишений.

Ключевые слова: Гаман, Просвещение, Сократ, аксиология, метасхематизм.
\end{abstract}

Поводом к написанию «Сократических достопримечательностей» (далее СД) И.Г.Гаманом послужили встречи с ним его бывшего работодателя Иоганна Кристофа Беренса и Иммануила Канта летом 1559 г., на которых ему было выдвинуто деловое предложение заняться переводом ряда статей энциклопедии Дидро и д’Аламбера для просвещения немецкой публики. Беренс и Кант надеялись, что вовлечённость в эту работу окажет воздействие на самого Гамана, пережившего своеобразное «обращение» в Лондоне годом ранее. Они стремились таким образом вернуть его к идеалам Просвещения.

Через некоторое время Гаман ответил отказом на это предложение, но ему требовалось ещё «объяснить себя». Собственно, СД и явились таким объяснением. Дебютную работу Гамана можно, таким образом, рассматривать в качестве апологетики его конкретного жизненного выбора и его мировоззрения в целом.

В вводной части трактата Гаман в своём особом неподражаемом стиле проводит социально-политическую критику режима просвещённого абсолютизма Фридриха II. Хотя эта проблематика не занимает основного места в трактате, но скорее создаёт общий фон для основной части работы, посвящённой оригинальной трактовке концепции «веры» Юма, а также обсуждению «незнания» и «гения» Сократа, всё же этот аспект данного сочинения Гамана заслуживает определённого внимания.

Гаман предельно заостряет проблематику морального выбора философа. На что может рассчитывать литератор, философ, интеллектуал его эпохи, если поиск истины он ставит выше, чем угождение власть предержащим? Отстаивая собственное мировоззрение, Гаман ставит аксиологическую дилемму перед представителями элиты, репрезентированными Беренсом и Кантом как двумя непосредственными адресатами его работы (Беренс представляет мир торговли, Кант - науки) [1. С. 35].

В качестве полигона для трансляции своих идей Гаман не случайно избрал личность Сократа. Как метод философствования Сократа, так и самоотверженное стремление к истине и особенно благородная смерть сделали его этическим эталоном для будущих поколений. Два парадоксальных момента 
жизни и смерти Сократа особенно впечатлили его современников и потомков: поразительное несоответствие его неказистого внешнего облика и внутреннего содержания [2. С. 178-179], что шло вразрез с калокагатией как общепринятой установкой греческой культуры, и удивительный переворот в событии его казни, при котором осужденная на смерть жертва сохранила честь, в то время как позор был уготован её судьям.

При переходе от античной философии к патристике произошла «христианизация» образа Сократа. С наступлением времени Просвещения маятник качнулся в противоположную сторону. Даже в сравнении с эпохой Ренессанса акцент был не на синтезе, но на противопоставлении греческой Античности и христианства наряду с критикой последнего.

Гаман устанавливает типологические взаимосвязи между собой и Сократом, в некотором смысле он воспринимает себя как Socrates redivivus, что не означает, что он претендует на нечто большее в сравнении с самим Сократом. Он просто смещает линии конфликта - вместо рафинированного рационалиста Сократа, представленного в современную эпоху в первую очередь деятелями французского Просвещения и берлинскими literati, которым, как они считали, противостоят ретроградные церковники, Сократ Гамана предстаёт как человек, осознавший недостаточность опоры на собственный разум.

Освальд Байер характеризует метасхематический подход Гамана следующим образом: «Он видит себя в зеркале других и других в зеркале собственных переживаний. Он помещает себя на их место, словно смотрит на мир их глазами» [3. S. 118]. Этот гамановский метод метасхематизма [4. P. 88-91; 5. S. 501-503] включает две части: (1) личную вовлечённость автора текста в описываемые им события (Гаман предстаёт в образе Сократа, надевает на себя, если угодно, маску Сократа); (2) непрямой способ передачи контента адресатам (Гаман представляет «метасхематически» отношения между собой и Беренсом и Кантом как отношения между Сократом и софистами его времени).

«Эстетическое подражание» Сократу, который, как известно, ничего не написал, в случае Гамана выражается, в частности, в том, что он пишет, словно ведёт диалог с читателем. Некоторые ясные утверждения трактата - как острова, между которыми нет переправы. Читателю предлагается достроить взаимосвязи, броситься вплавь. То есть от него требуется не только теоретическое осмысление проблемы, но и практическая вовлечённость, не только интеллектуальное согласие либо несогласие, но связанный с этим жизненный выбор.

\section{Lange Weile}

Вплетая особым образом социально-политическую проблематику в структуру СД, Гаман показывает его позицию в отношении культурной и мировоззренческой экспансии идей французского Просвещения в Пруссии.

Полное название работы сразу интригует: «Сократические достопримечательности для скуки (lange Weile) публики, собранные любителем досуга (langen Weile). С двойным посвящением для Никого и Двоих». Такой заголовок требует интерпретации как минимум двух ключевых понятий: lange Weile (скука, досуг) и «публика».

В каком смысле Гаман использует понятие lange Weile? В эпоху Просвещения главным достоинством считался труд. Даже внешне бессмыслен- 
ный труд, служащий поддержанию роскоши, способствует процветанию всего общества, как утверждается в «Персидских письмах» Монтескьё [6. С. 173]. В «О духе законов» Монтескьё заявляет, что использование разума позволяет человеку заниматься любым тяжелым трудом. Даже про труд в рудниках, который ранее выполняли только рабы и преступники, он говорит, что «люди, занимающиеся им, живут вполне счастливо» [7. С. 225]. Такие представления получили развитие и в немецкой версии Просвещения: «Во время немецкого Просвещения возникло представление о работе как деятельности, которая приводит к счастью... Феодальный или паразитический буржуазный образ жизни, не подразумевавший труда, регулярно отвергался в романах, трактатах и пособиях по самосовершенствованию. Праздность, зачастую связываемая со скукой, осуждалась как по религиозным... так и политическим причинам, в виде критики аристократии. Напротив, работа подразумевала только положительные коннотации, такие как счастье, удовольствие, Bildung (личный рост) и образование» [8. С. 1436].

Учитывая обстоятельства жизни Гамана, который в то время находился на иждивении отца, разумно предположить, что Беренс осуждал его за праздность. С самого начала «Сократических достопримечательностей» Гаман выступает против такой трудовой этики, которая не даёт человеку задуматься о насущных вопросах бытия, делает его винтиком большой государственной машины. Этому он противопоставляет концепцию Лютера sola gratia: удовлетворение приобретается не в результате тяжелых усилий, но даётся gratis, даром. С присущей ему иронией Гаман употребляет понятие lange Weile в двух смыслах. Для «публики» это бессмысленное времяпрепровождение (поскольку бессмысленна и сама «публика»), скука, которую Гаман, как может показаться на первый взгляд, стремится прогнать подобно тому, как это делают прочие авторы. Применительно же к самому Гаману это понятие здесь не имеет отрицательного смысла, вопреки мнению Гильманова, который отмечает, что Гаман «знал ползучую силу скуки» до его лондонского обращения [9. С. 184]. В этом втором значении lange Weile означает скорее досуг, свободное времяпрепровождение [10. С. 105]. В частности, именно в этом значении Гаман использует данную конструкцию, говоря в «Облаках», трактате-послесловии к СД, о «пароксизме досуга», который был у ап. Павла в Афинах [Там же]. «Скука публики» - эфемерное понятие, которое использовалось власть предержащими для удовлетворения своих личных интересов, «досуг» же Гамана характеризует его позицию свободного человека, удовлетворённого собой. После завершения работы над трактатом Гаман отмечает: «Я работал над этим исследованием с упоением, и... оно получилось у меня, как я того желал. Поскольку сам собой я могу быть доволен, я мало завишу от приёма у публики» [11. С. 410]. Несомненно, такая позиция имеет прямую корреляцию с жизненным выбором самого Гамана, отказавшегося от публичной карьеры, при которой ему пришлось бы идти на компромиссы, предпочтя ей свободное творчество.

\section{Публика как «никто»}

«Никто» и «двое» в посвященни титульной страницы трактата означают соответственно публику и Беренса с Кантом. Мнение, что «никто» - сам Гаман [12. С. 57], не может быть признано до конца удовлетворительным по 
причине очевидного отождествления публики с «никто» в обращении к публике. Действительно, Гаман использует строфу из «Киклопа» Еврипида о «никто» [10. С. 59], так что можно подумать, что он представляет себя хитроумным Одиссеем, обманувшим публику-Полифема. Однако главный аргумент Гамана направлен против «публики» как абстрактного понятия, которому воздают тщетное поклонение, притом что публика не способна слышать, видеть и понимать, иначе говоря, не имеет референта в мире реальных вещей.

В нелюбви Гамана к абстракциям проявляются его номиналистские тенденции, вполне уместные для него как последователя теологии Лютера, хотя встречаются и попытки интерпретировать Гамана как «тонкой разновидности реалиста» [13. С. 27-28]. Такое отношение к абстракциям привело Гамана к провозглашению мнимости публики как понятия и в ещё большей степени к мнению о тщетности преклонения перед публикой.

Для стиля Гамана в этом месте характерна достаточно острая ирония, причём не как временное снятие напряжённости, позволяющее далее сконцентрироваться на серьёзных вопросах, но как часть его стиля и метода философствовования. Так, его обращение к публике построено в виде молитвы к несуществующему идолу публики, который уподоблен тупому ничего не понимающему циклопу (именно в этой связи Гаман цитирует одноименную пьесу Еврипида). Кушанье СД обратит этого адресата в ничто подобно тому, как кушанье Даниила разорвало идола Вила в Дан 14 : 27. На реальных же адресатов СД - Беренса и Канта - этот пирожок, как утверждает Гаман, подействует в качестве слабительного, очистив их для служения истине, которую он, Гаман, возвещает [10. С. 59].

Гаману действительно важны отдельные личности, к которым он обращается, в первую очередь двое его конкретных адресатов [Там же. С. 61], а не понятие «публика», попытка угождения которой скрывает тот факт, что бенефициаром таких действий становится элита, а не конкретные эксплуатируемые люди, исчезающие за абстрактным понятием «публики».

\section{Аксиологическая альтернатива}

Политическая направленность окончания трактата образует своеобразную inclusio с его началом, позволяющее видеть политический подтекст во всей работе, хотя он и не выражен так явно, как в более поздних работах Гамана, написанных на французском языке.

Перед читателем СД ставится нелегкий выбор: служить истине подобно тому, как это делал Сократ и, предположительно, делает Гаман, что подразумевает жизнь, полную лишений, либо «раболепствовать и блюдолизничать» [Там же. С. 82]. Этим занимаются современные софисты, деятели Просвещения в Берлине, обучившиеся этой науке у своих французских аналогов. Обращаясь к публике, декларируя намерения о её просвещении, они фактически обслуживают интересы правящей верхушки. Согласно Гаману, устраняя авторитет традиции, общество не приходит к большей свободе, но, постулируя автономию разума, меняет одно поклонение на другое. Это новое рабство для него неприемлемо. Себя Гаман рассматривает как свободного человека, который позволяет себе плыть против течения и не подчиняться мнению большинства, даже если тем самым он лишает себя дивидендов, которые ему сулила бы более коллаборационистская позиция. Сам Гаман готов жить «от 
крох». К такому же выбору он пытается склонить Беренса и Канта - предприятие, оказавшееся в итоге совершенно безнадёжным. В этом упоминании о крохах - тройная аллюзия на насыщающие крохи Христа в Мф $15: 27$, окончание платоновского диалога «Гиппий Большой» («шелуха и обрывки речей» [14. С. 416] и собственную раннюю работу с одноименным названием (“Brocken”), которую он, впрочем, не публиковал.

Итак, Гаман заключает, что философия как любовь к истине не приносит, как правило, земного счастья или временных благ тем, кто её практикует. Философ не должен удивляться отсутствию признания у публики. Его удел «питание от крох» как аналог смерти Сократа от рук афинян, поступающие же против совести должны довольствоваться прислуживанием интересам высших классов, забыв о своём высоком предназначении.

\section{Литература}

1. Sparling R.A. Johann Georg Hamann and the Enlightenment Project. Toronto : University of Toronto Press, 2011.

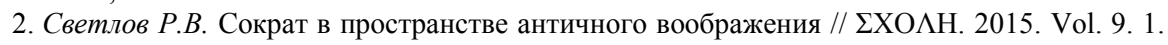
C. $169-184$.

3. Bayer $O$. Zeitgenosse im Widerspruch. J.G. Hamann als radicaler Aufklärer. München; Zürich, 1988. S. 118.

4. O'Flaherty J. C., trans. and ed. Socratic Memorabilia: A Translation and Commentary. Baltimore: The John Hopkins Press, 1967.

5. Unger R. Hamann und die Aufklärung. Halle, 1925.

6. Монтескье Ш.Л. Персидские письма. Размышления о причинах величия и падения римлян. М. : Канон-пресс-Ц, 2002.

7. Монтескье Ш.Л. Избранные произведения о духе законов. М., 2011.

8. Delon M. Encyclopedia of the Enlightenment. Routledge, 2013.

9. Гильманов В.X. Гаман и литература Просвещения : (Опыт универсальной герменевтики) : дис. ... д-ра филол. наук. Калининград, 2006.

10. Hamann J.G. Sämtliche Werke. 6 Bde. Historisch-kritische Ausgabe von J. Nadler. Wien : Herder, 1949-1957. Bd 2. S. 57-109.

11. Hamann J.G. Briefwechsel. 6 Bde von Walther Ziesemer und Arthur Henkel. Wiesbaden : Insel, 1955-1975. 160. An Iohann Gotthelf Lindner, Königsberg, den. 11 Sept. 1759. Bd. 1. S. 408411.

12. De Pascale, Carla. Il razionale e l'irrazionale. La filosofia critica tra Hamann e Schopenhauer. Edizioni ETS, № 134. Pisa : Edizioni ETS, 2014. P. 57.

13. Milbank $J$. "Knowledge: The Theological Critique of Philosophy in Hamann and Jacobi" // Radical Orthodoxy: A New Theology, ed. by John Milbank, Catherine Pickstock, and Graham Ward. London : Routledge, 1999. P. 21-37.

14. Платон. Собрание сочинений: в 4 т. М. : Институт философии РАН, 1993. Т. 1.

Alexey M. Streltsov, Theological Seminary of Siberian Evangelical Lutheran Church (Novosibirsk, Russian Federation); Novosibirsk State University (Novosibirsk, Russian Federation).

E-mail: streltsov@mail.ru

Vestnik Tomskogo gosudarstvennogo universiteta. Filosofiya. Sotsiologiya. Politologiya - Tomsk State University Journal of Philosophy, Sociology and Political Science. 2018. 43. pp. 111-116.

DOI: $10.17223 / 1998863 X / 43 / 10$

AXIOLOGICAL PROBLEMS OF THE PHILOSOPHER'S CALLING IN HAMANN'S SOCRATIC MEMORABILIA

Keywords: Hamann; Enlightenment; Socrates; axiology; metaschematism.

The paper analyses the social-political ramifications of Johann Georg Hamann's 1759 debut treatise Socratic Memorabilia, in which he challenges the cultural and ideological expansion of the ideas of the French Enlightenment in Prussia. Using his own "metaschematism" method, Hamann takes the role of a Socrates of his own time and criticises the policy of enlightened absolutism of Frederick the 
Great. He poses an axiological alternative to his addressees Immanuel Kant and Johann Christoph Berens: serving the truth irrespective of the consequences or conscientious pleasing those in authority under the slogan of enlightening the public. Hamann rejects the labour ethic of the Enlightenment, which praised even hard and meaningless labour for the sake of the flourishing of society. Instead, he proposes the concept of "leisure" (Lange Weile), which allows him to preserve the freedom of creativity. Hamann attempts to destroy the concept of the public as a societal ideal by viewing it as an abstraction that does not have a referent in the real world. Being a widely spread practice in the Enlightenment context, an attempt to please the public would conceal the fact that it is the elite (and not specific people hidden behind the terminology of the "public" who are being exploited) that becomes the beneficiary of such activities. According to Hamann, a philosopher who views his calling highly will not necessarily count on wide recognition by society, but must be ready to be misunderstood and lead a life full of hardships.

\section{References}

1. Sparling, R.A. (2011) Johann Georg Hamann and the Enlightenment Project. Toronto: University of Toronto Press.

2. Svetlov, R. (2015) Socrates in the context of the ancient imagination. $\Sigma X O \Lambda H .9(1)$. pp. 169184. (In Russian).

3. Bayer, O. (1988) Zeitgenosse im Widerspruch. J. G. Hamann als radicaler Aufklärer [Contemporary in contradiction. J.G. Hamann as a radical enlightener]. München, Zürich: Piper.

4. O'Flaherty, J.C. (1967) Socratic Memorabilia: A Translation and Commentary. Baltimore: The John Hopkins Press.

5. Unger, R. (1925) Hamann und die Aufklärung. Halle: Niemeyer.

6. Montesquieu, Ch.L. (2002) Persidskiye pis'ma. Razmyshleniya o prichinakh velichiya I padeniya rimlyan [Persian letters. Reflections on the Causes of the Greatness and Fall of the Romans]. Translated from French by N. Sarkitov. Moscow: Kanon-press.

7. Montesquieu, Ch.L. (2011) Izbrannye proizvedeniya o dukhe zakonov [On the Spirit of the Laws]. Translated from French. Moscow: [s.n.].

8. Delon, M. (2013) Encyclopedia of the Enlightenment. Routledge.

9. Gilmanov, V.Kh. (2006) Gaman i literatura Prosvescheniya (Opyt universal'noy germenevtiki) [Hamann and Enlightenment Literature (Experience of Universal Hermeneutics). Phylology Dr. Diss. Kaliningrad. 57-109.

10. Hamann, J.G. (1949-1957) Sämtliche Werke [Collected Works]. Vol. 6. Vienna: Herder. pp.

11. Hamann, J.G. (1955-1975) Briefwechsel. 6 Bde von Walther Ziesemer und Arthur Henkel. Vol. 1. Wiesbaden: Insel. pp. 408-411.

12. De Pascale, C. (2014) Il razionale e l'irrazionale. La filosofia critica tra Hamann e Schopenhauer [The rational and the irrational. The critical philosophy between Hamann and Schopenhauer]. Edizioni ETS.

13. Milbank, J. (1999) Knowledge: The Theological Critique of Philosophy in Hamann and Jacobi. In: Milbank, J., Pickstock, C. \& Ward, G. (eds) Radical Orthodoxy: A New Theology. London: Routledge. pp. 21-37.

14. Plato. (1993) Sobraniye sochineniy v $4 t$. [Works in 4 vols]. Vol. 1. Moscow: Institute of Philosophy RAS. 